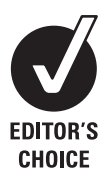

European School of Molecular
Medicine (SEMM), Milan, Italy

${ }^{2}$ Firc Institute of Molecular

Oncology (IFOM), Milan, Italy;

${ }^{3}$ University of Milan, Milan, Italy

Correspondence to:

Miss S Camporesi, c/o IFOM-IEO

Campus, Via Adamello 16,

20139 Milan, Italy; silvia.

camporesi@ifom-ieo-campus.it

Received 14 February 2008

Revised 14 May 2008

Accepted 23 May 2008

\title{
Fearing a non-existing Minotaur? The ethical challenges of research on cytoplasmic hybrid embryos
}

\author{
S Camporesi, ${ }^{1,3}$ G Boniolo $0^{1,2,3}$
}

\section{ABSTRACT}

In this paper we address the ethical challenges of research on cytoplasmic hybrid embryos, or "cybrids". The controversial pronouncement of the UK's Human Embryology and Fertilisation Authority of September 2007 on the permissibility of this area of research is the starting point of our discussion, and we argue in its favour. By a rigorous definition of the entities at issue, we show how the terms "chimera" and "hybrid" are improper in the case of cybrids, and how their use can bias the debate creating moral prejudices. After analysing the scientific aspects of cybrids research and sketching out current alternatives, we enter the ethical debate, starting from the premise that research on early human embryos is ethically permissible under some circumstances. We emphasise how research on cybrids has positive consequences in terms of scientific and therapeutic applications, since it allows the derivation of human embryonic stem cells genetically tailored to the somatic cell donor. Such cell lines offer a unique in vitro model both for studies of human pathogenesis and for drug screening and discovery. Research on cybrids also circumvents the problem of the scarcity of human oocytes and their ethically dubious donation. Finally, we object to the most common arguments against cybrids research, that is, moral repugnance, the slippery slope argument, the appeal to "nature", and the unfair distribution of economical resources.

What are cytoplasmic hybrid embryos, also known as "cybrids"? Chimeras, hybrids or something else? They have been the object of a firestorm of controversy in the media, after the September 2007 decision of the UK's Human Fertilisation and Embryology Authority (HFEA) to permit research on them. ${ }^{1}$ But what are they precisely? In the following, we will first define the terms at issue, since a good ethical debate cannot begin without a punctual clarification of what we are speaking of. Then we will address the rationale of the use of animal oocytes in somatic cellular nuclear transfer (SCNT), and analyse whether alternatives exist. Eventually we will propose arguments in favour of research on cybrids and reply to the main objections, thus arguing in support of the HFEA decision.

\section{WHAT WE ARE NOT SPEAKING OF}

What are the entities referred to in the HFEA decision? The media have often called them "chimeras" or "hybrids", thus contributing fuel to the controversy, by evoking images of mythological creatures such as the Minotaur and Homer's chimera, the fire breathing monster with a lion's head, a goat's body and a serpent's tail. Such an erroneous association has generated a moral prejudice, as we will argue later. That explains why it is so important to define precisely the terms at issue and, therefore, to indicate correctly what we are speaking of.

What exactly is a chimera? In the commonsense language, it is either a mythological figure, or-by synecdochical enlargement-something illusory or impossible to achieve. ${ }^{2}$ In biology, by chimera we mean a living being composed of two or more different populations of genetically distinct cells originated in different zygotes. ${ }^{3}$ There are different types of spontaneous chimeras occurring in nature during the fertilisation process, also in humans. ${ }^{4}$ Nowadays different types of chimeras are routinely used in biological research, both within the same species (eg, it is common laboratory practice to create chimeric mice $)^{5}$ and between different species (the so-called "interspecific chimeras"). ${ }^{6}$ "Human-to-animal" chimeras have been routinely produced for decades by xenografts of human embryonic stem cells into immune deficient mice to test their pluripotency capacity.? Xenotransplantations are other more manifest instances of human-animal mixing. The opposite type of interspecific chimera would be an "animalto-human chimera", created through the integration of animal cells in a human embryo. Such entities are banned under HFEA legislation, and no scientist has asked for such a license.

As a first conclusion, the HFEA decision of September 2007 regards neither human-to-animal chimeras (ethical recommendations in Europe already exist for these), ${ }^{8}$ nor animal-to-human chimeras (which are totally forbidden), but not even, of course, the mythological entities! Does the HFEA decision concern hybrids?

In biology, a hybrid is the offspring of two living beings of different species that results from the fertilisation of the oocyte of one species by the spermatozoon of a different species. Hybrids differ from chimeras in having a uniform karyotype (ie, number, form and size of chromosomes), and in being very often sterile, as it happens with mules and hinnies. ${ }^{9}$ True human-animal hybrid embryos are banned under the current HFEA legislation, with the exception of specific cases of procedures of assisted reproduction, when a test can be done to verify the capacity of spermatozoa to penetrate an animal oocyte membrane. Such embryos are, however, destructed immediately after the test is performed. ${ }^{10}$ If the right term to refer to the entities 
of the HFEA decision is neither chimera nor hybrid, what are we speaking of?

\section{WHAT WE ARE SPEAKING OF}

\section{A modification of somatic cellular nuclear transfer}

In the HFEA official document, we read that "cytoplasmic hybrid embryos" are embryos derived from an animal oocyte depleted of its nucleus and inserted with the nucleus of a human somatic cell. The procedure involved is called interspecies somatic cell nuclear transfer (iSCNT), which differs from the "traditional" SCNT ${ }^{11}$ insofar as the recipient cell does not belong to the same species of the donor. The resulting cell still contains a small amount of animal DNA (less than 1\%), coming from the mitochondria of the recipient oocyte. Likely human mitochondria will be present as well, ${ }^{12}$ conferring to embryos derived from iSCNT variable degrees of heteroplasmy, or presence of a mixture of mitochondrial genome derived from the two species. From a genetic point of view, the embryo resulting from iSCNT is more similar to a clone of the somatic cell donor, than to a hybrid embryo.

Upon activation with an electrical stimulus or a calcium ionophore, which mimic the event of fertilisation, cell division is triggered. When the stage of early blastocyst is reached $\left(4^{\circ}-\right.$ $5^{\circ}$ days, 70-100 cells) researchers seek to establish human embryonic stem cells ( $\mathrm{hES}$ ) from the inner cell mass. ${ }^{313}$ Quoting embryologist Anne McLaren, "any stem cells derived from these [ie, iSCNT] would be essentially human", since it is the human nuclear DNA which confers species and genetic identity. ${ }^{14}$

The hES cell lines derived from iSCNT are genetically tailored and immunologically compatible with the somatic cell donor, and foster unique applications, which we will discuss later. There has been at least one report of successful hES cell line derivation following SCNT of adult human fibroblasts into enucleated rabbit oocytes, ${ }^{15}$ and another more controversial into bovine oocytes. ${ }^{16}$ Although the status of the rabbit/human mitochondria was not addressed in Chen's paper, ${ }^{15}$ the expectation is that the transfer of an intact human cell into an enucleated rabbit oocyte would result in the rabbit proteins and mitochondria being replaced with human versions over time. ${ }^{17}$ Primate embryonic stem cells have also been derived following intraspecies nuclear transfer in monkeys. ${ }^{18}$

In November 2006 two research groups in the UK (the Stem Cell Biology Laboratory at the Kings College in London, directed by Dr Stephen Minger, and the group headed by Dr Lyle Armstrong and based at the University of Newcastle Upon Tyne) asked HFEA for a license to carry out iSCNT. Their request prompted a consultation period on the subject, which lasted from April till July 2007, and resulted in a vivid public debate on a number of issues, ranging from purely scientific ones to much broader societal issues, such as the role of public and scientific opinion in influencing regulation and government policy. A "partial green light" was given with the HFEA pronouncement of September 2007': a formal recognition that this line of research can, with caution and careful scrutiny, be permitted, even if each project must still be evaluated singularly. On 17 January 2008 the HFEA licensed permission to the two groups to pursue their investigation. ${ }^{19}$ In particular, the group at Newcastle Upon Tyne proposes "to study how the nucleus is reprogrammed during embryonic development, to compare the derived embryonic stem cell lines derived from iSCNT with stem cell lines derived from embryos created from in vitro fertilisation procedures". ${ }^{20}$ Instead, Dr Minger's group aims at isolating fibroblasts from patients suffering from genetic neurodegenerative diseases, in order to produce disease specific cell lines which could "ultimately be available to the wider scientific community for the advancement of research into serious genetic disease". ${ }^{21}$

\section{The pragmatic rationale of the use of animal oocytes}

What are the reasons for the use of animal oocytes in SCNT? The answer lies in the shortage of human oocytes for research. ${ }^{22}$ The most readily available oocytes are aged ones which failed to be fertilised in vitro, but so far they have been unsuitable recipients for SCNT. This may be due to a number of factors including oocyte aneuploidy (ie, chromosome aberrations), disorganised meiotic spindles, aberrant expression of microtubule proteins and altered expression of crucial oocyte-specific genes. ${ }^{23}$

The alternative would be fresh unfertilised oocytes from donor women, but there are substantial logistical, medical and ethical hindrances which make it undesirable, as we will discuss later on.

Other existing alternatives are all problematic from either a technical or an ethical standpoint. Here we are only going to mention them, without entering into the details. Note, however, that the existence of alternatives does not imply that they are mutually exclusive. Instead we believe that they should all be pursued to increase knowledge in this field.

One alternative was proposed in the laboratory directed by Kevin Eggan in June 2007..4 The researchers used fertilised mouse zygotes reversibly arrested in mitosis as recipient cells for SCNT. Their approach, the authors claim, could provide a valid alternative for solving the problem of human oocyte shortage, their fertilised zygotes used as recipient in SCNT being supernumerary from in vitro fertilisation procedures in humans. Also, superfertilised human embryos, which are destined to be discarded, could be used. Although relevant, this alternative has not been demonstrated yet to be feasible in humans. In addition, this approach is technically much more challenging, and much less efficient, than traditional SCNT or iSCNT (already not efficient at all), ${ }^{12}$ because it concerns the depletion of the host cell by micromanipulation of its chromosomes, not of the nucleus.

Other alternatives, as the differentiation of human oocytes from hES cell lines and from somatic cells, have been explored, but currently stand as undeliverable approaches in humans. ${ }^{22}$ Recently, Takahashi and Yamanaka discovered that four factors are critical for reprogramming adult somatic nuclei. They were able to induce pluripotent ES-like cells (which they named iPS, for induced pluripotent stem cells) from embryonic and adult mice fibroblasts by overexpression of four specific genes (Oct3/ 4, Sox-2, c-Myc and Klf4) in ES cell culture conditions. ${ }^{25}$ In November 2007 pluripotent stem cells were also obtained from adult human skin fibroblasts. ${ }^{26}{ }^{27}$ From this novel technique great developments are awaited, but up to now applications in humans are hindered by the fact that we do not know exactly the consequences of the insertion of these four transgenes by means of retroviral transduction. It remains to be determined whether induced pluripotent cells could lead to cancer or other diseases after transplantation. ${ }^{28}$ Besides, although human iPS cells are similar to hES cells, they are not identical, as DNA microarray data have demonstrated that at least $\sim 1300$ genes display more than fivefold difference in expression levels. ${ }^{26}$ As Herbert Gottweis and Stephen Minger rightly point out, ${ }^{28}$ "a great deal of fundamental basic comparative research must be performed before we will know for certain whether iPS cells have the same therapeutic and research potential as hES cells". 


\section{THE ETHICAL CHALLENGES}

Our premise to the ethical discussion on the creation and use of cybrids is that, under some circumstances, research on early human embryos is ethically permissible. ${ }^{29}$ Starting from this claim, we now focus on the ethical arguments regarding cybrids research. First, we will advance arguments in its favour, and then address the main objections.

\section{Arguments in favour}

The appeal to the positive consequences in terms of scientific and therapeutic applications is the strongest argument in favour of research on cybrids. The most relevant consequence of the production of cybrids is the derivation of hES cells genetically tailored to the somatic cell donor, which would foster a manifold of important applications.

First, they would represent an in vitro cellular model for the study of disease development and for screening compounds, since nuclei from somatic cells donated from patients could be used to generate disease-specific hES cell lines, ${ }^{30}$ for example, Alzheimer disease, Parkinson disease and other progressive neurological disorders, including motor neuron disease and spinal muscular atrophy, for which there are no therapies whatsoever. From the point of view of more basic research, cybrids would provide a new model for studying nuclear cytoplasmic interactions, nucleus reprogramming and cell differentiation during embryo development. In the longer term, this knowledge will help understanding of the optimal way to produce pluripotent cells and to drive differentiation. It will also help understanding of the molecular and cellular events involved in disease processes, which eventually could open up new avenues for treatment of pathologies. Note that the groups headed by Dr Minger and Dr Armstrong will focus, respectively, on the applied and on the basic research aspects of cybrids. Another application, but outside the field, could be the production of live offspring for the preservation/rescue of endangered species, which a few studies have already successfully achieved in gaur, mouflon and African wild cat. ${ }^{31}$

The emergence of new technologies for the reprogramming of adult somatic cells, ${ }^{26-28}$ as already mentioned, does not obviate the need for research on cybrids. Instead, research on the two fields should be pursued in parallel, for the very reason that understanding the processes of cell differentiation and reprogramming is still at an early stage. It is, therefore, even more important for researchers to have the opportunity of using different model systems, in order to obtain a deeper understanding of the molecular and cellular events involved. Science does not work and progress by "independent compartments". Thus, we should always be aware that blocking research in one field is not deleterious only to that field, but to many contiguous fields, and as we know from the history of science, important discoveries often result from synergistic efforts pursued through different routes, but aimed in the same direction. Even the authors of the key iPS cell papers ${ }^{25-27}$ have argued that it would be dangerous to invest all hopes in a single approach. $^{28}$

Besides the scientific aspects, the use of cybrids seems an ethically more acceptable alternative than the use of human oocytes in research. Oocyte donation is a very demanding physical process, with its hormonal induction treatment causing manifestations of ovarian hyper stimulation syndrome in up to one third of treated women. Severe forms requiring hospitalisation and potentially life-threatening are less common but by no means rare. ${ }^{32}$ Risks for women's health are not the only issue at stake: the number of oocytes obtainable by donation would still be very limited compared to the thousands required in SCNT for ES cell derivation (the efficiency of derivation of ES cells from oocytes in primate is only $0.7 \%$ ). ${ }^{17}$ There is also the issue concerning the ethically dubious financial incentives to encourage donations (this practice is widespread in the US; for a fair ethical analysis of pro and contra see ${ }^{33}{ }^{34}$ ).

The production of cybrids through iSCNT side-steps these problems. But this does not imply that other alternatives should not be looked for and actively pursued.

\section{Arguments against}

Some people may feel an instinctive moral repugnance towards the prospect of creating cybrids. However, precisely because this is not a rational position, but a position based upon an instinctive, visceral reaction to something thought of as deserving disgust, it is very difficult to deal with it in a rational discussion. We are not suggesting here that such reactions are completely meaningless for the formations of our moral judgments. On the contrary, they could be an emotional starting point, which, nevertheless, should be elaborated and supported with rational arguments in order to construct a moral judgment, along Martha Nussbaum lines her publication Hiding from humanity. Disgust, shame, and the law..$^{35}$ Otherwise, they would remain visceral reactions formalised as moral prejudices. Hopefully most of such instinctive reactions will disappear after a correct definition and explanation of the entities at stake in the ethical detate are provided, such as ours in sections two and three. Unfortunately, in the case of cybrids incorrect information from the media has concurred to the formation of a moral prejudice based on a visceral reaction, by associating to cybrids images of monsters such as the Minotaur or Homer's firebreathing chimera.

Another of the most common objections to the creation of cybrids is based on the "slippery slope argument", according to which even though A alone could be acceptable, permitting it creates a precedent that leads-through a long chain of supposed logical relationships-to permitting B, which is considered morally unacceptable.

In the context of research on cybrids, the argument could be formulated in (a) a strong version and (b) a weak version. In (a), the slippery slope from the production of cybrids would lead to the possibility of their implantation in a woman's uterus, and in (b) to the permissibility of a contiguous research area considered morally unacceptable (ie, research on true human-animal hybrids, or on animal-to-human chimeras). On the slippery slope argument and on its either wrong or fragile application against new biotechnological outcomes there is a vivid debate, to which we have contributed elsewhere. ${ }^{29}{ }^{35}$ Here it suffices to reply to (a) by saying that no scientist has ever expressed a similar interest. The same can be replied to (b). Of course, it is not said that it will not happen in the future. This is true, but if scientists will want to pursue the creation of true hybrids or animal-to-human chimeras, we do not see any reason why their project should not be carefully examined by the HFEA (or alike) and possibly rejected.

According to a third objection, researchers producing cybrids act "against nature". This argument surfaces again and again in many different contexts of biomedical research, but it should not concern us for at least two reasons. The first concerns the meaning of the term "nature": in which sense do we use it? It does not have only one meaning, and one referent. Certainly, it is not for us to enter into such an ancient and thorny issue here. Nevertheless, it is worth recalling that there is a general consensus regarding the fact that the distinction natural-unnatural is not so 
sharp, but represents a continuum of degrees. In other words, "natural" and "unnatural" are (in a technical sense) complementary vague concepts. ${ }^{36}$ Someone could claim that, even though we cannot draw a sharp distinction between the two concepts, but there are clear-cut cases at the two extremes, and cybrids would be at the unnatural end. But this implies neither that the distinction natural-unnatural nor being unnatural have, per se, a moral significance. ${ }^{37}$ Are earthquakes and tornados good? Are human prevention strategies and technologies to cope with them bad? These examples show that, even accepting that cybrids are unnatural, this would not imply that the actions aimed at producing them are intrinsically evil or immoral. The problem regarding the "natural" status of the cybrids may be interesting from the ontological point of view, but it is not said that its solution affects the problem of the morality of the acts involved in their production. The goodness and the badness do not seem to lie in the world, but in our ethical way of valuing human actions. ${ }^{38}$ Quoting from Stephen Jay Gould: "The answers [of morality] will not be read passively from nature; they do not, and cannot, arise from the data of science". ${ }^{39}$ For our final remarks on this issue, we wish to recall both that we can do ethics without ontology ${ }^{40}$ and Hume's claim, according to which, a moral conclusion cannot be validly inferred from non-moral premises. None of these issues is immune from criticisms; but the burden of proof lies on the shoulders of those who object to research on cybrids on the basis of some ontological assumption or of those who ethically question the creation of cybrids on the basis of an infringement of Hume's claim, then the burden of proof is on her. Ultimately, we think that our concept of what is "natural" depends on what we are used to, and therefore it is not a static concept, but will continue to evolve with us. In the meantime, we should not allow it to distract us from the rational consideration of the ethical challenges of research on cybrids. ${ }^{41}$

Finally, others could point out that economical resources dedicated to the research on cybrids, whose therapeutic effects would most likely regard only the elite, could be better allocated if they were addressed to world pandemics, such as AIDS. A consistent application of this argument would require us stop the research on the causes of, and the therapies for, the very rare diseases. There are about 5000 "orphan diseases", rare disorders which have not been "adopted" by the pharmaceutical industry because they provide too little financial incentive. Should we really stop researching them?

It should be noted that both in the case of hES cells derived from cybrids and in the case of world pandemics, the real problem does not concern the availability of therapies, but the access to them. In the case of AIDS, there are indeed drugs allowing people to live with the disease all life long, but only a very small portion of them can afford such expensive cocktailtherapies.

As a last remark, it is undeniable that the progress of knowledge in one field is likely to increase knowledge in contiguous fields. But are those who object to research on cybrids ready to reject possible future developments/applications deriving from this field, which they consider morally wrong?

\section{CONCLUSION}

We first showed that the terms "chimera" and "hybrid" are improper in the case of cybrids, and that their use can bias the ethical debate by creating moral prejudices. We then approached the biology underlying cybrids, emphasising how iSCNT differs from "traditional" SCNT, since the recipient oocytes derives from rabbits or cows.
After analysing the scientific aspects of cybrids research and sketching out current alternatives, we entered the ethical arena, starting from the premise that research on early human embryos is ethically permissible in some circumstances. ${ }^{29} \mathrm{We}$ argued in favour of cybrids research, emphasising the positive consequences in terms of scientific and therapeutic applications. The hES cells derived from cybrids would be genetically tailored to the somatic cell donor and would offer a unique in vitro model both for studies regarding human pathogenesis and the molecular processes of cell differentiation, embryo development and reprogramming. Also, the use of recipient animal oocytes in iSCNT would side-step the ethical issue of the use of human donor oocytes for research. ${ }^{14}$ 32-34

We also addressed the most common objections - the moral repugnance, the slippery slope argument, the appeal to "nature" and the unfair distribution of economical resources-and pointed out their weaknesses.

One could object that our counter-arguments are not so cybrid-specific. While this is true, it is unavoidable since, as far as we know, there are no really specific rational objections to research on cybrids. That is, the possible non-specificity of our counter-objections is dependent on the actual non-specificity of the objections! We believe this to be one of the main weaknesses of the debate against cybrids. To note that the only exception could be the position grounded on moral repugnance and disgust, but such visceral reactions, if not supported by rational arguments, cannot be regarded as sound reasons to stop researching on cybrids.

It should be noted, on the other hand, that a strong objection to research on cybrids could be based on objecting to research on early human embryos in toto (assuming, as we did, ${ }^{4}$ that such cytoplasmic hybrid embryos would be essentially human). But, for the purposes of this paper, we assumed as the premise of our discussion that this kind of research is morally plausible. ${ }^{29}$

Taking into account all of the above, we find no persuasive reason to ban research on cybrids. Consequently we argue that the HFEA decision on the permissibility of research in this field is to be considered positively from the ethical point of view.

To conclude, we want to stress that only a correct knowledge of what scientists are doing in the human embryology and stem cell research fields can be the right and necessary starting point for a sound ethical debate. Otherwise, the risk we run is to end up in a labyrinth of false beliefs and deceiving mirrors, maybe fearing a non-existing Minotaur.

On 30 June 2008, an HFEA Licence Committee has approved an application from the group lead by Dr Justin St John at the University of Warwick for the creation of cybrids using pig oocytes.

Acknowledgements: We are very grateful to L Bortolotti, S Giaimo, A Blasimme, C Segrè, M Curnutte and G Testa for their sharp comments on earlier drafts of this paper. Moreover, we want to thank S Minger for scientific clarifications, S lotti and $\mathrm{G}$ Cenacchi for precious feedbacks to a seminar on this topic.

Competing interests: None.

\section{REFERENCES}

1. Human Fertilisation and Embryo Authority. HFEA statement on its decision regarding hybrid embryos. 5 Sep 2007. http://www.hfea.gov.uk/en/1581.html (accessed 24 Sep 2008).

2. Oxford English Dictionary definition for chimera. http://www.askoxford.com/ concise_oed/chimera?view = uk (accessed 24 Sep 2008).

3. Tecirlioglu RT, Guo J, Trounson A0, et al. Interspecies somatic cell nuclear transfer and preliminary data for horse-cow/mouse iSCNT. Stem Cell Rev 2006;2:277-87.

4. Malan V, Vekemans M, Turleau C, et al. Chimera and other fertilization errors. Clin Genet 2006;70:363-73. 
5. Eggan K, Akutsu H, Loring J, et al. Hybrid vigor, fetal overgrowth, and viability of mice derived by nuclear cloning and tetraploid embryo complementation. PNAS 2001;98:6209-14.

6. Behringer RB. Human-animal chimeras in biomedical research. Cell stem cell 2007;:1:259-62.

7. Lensch WM, Schlaeger MT, Zon LI, et al. Teratoma formation assays with human embryonic stem cells: a rationale for one type of human-animal chimera. Cell Stem Cell 2007;1:253-8.

8. Hyun I, Taylor P, Testa G, et al. Ethical standards for human to animal experiments in stem cell research. Cell Stem Cell 2007:1:159-63.

9. Short RV. The contribution of the mule to scientific thought. J Reprod Fertil 1975;23:359-64.

10. Department of Health. Human Tissue and Embryo (Draft) Bill. 17 May 2007:98-9. http://www.dh.gov.uk/en/Publicationsandstatistics/Publications/ PublicationsLegislation/DH 074718 (accessed 24 Sep 2008).

11. Wilmut I, Schnieke AE, McWhir J, et al. Viable offspring derived from fetal and adult mammalian cells. Nature 1997;385:810-3.

12. Beyhan Z, lager AE, Cibelli JB. Interspecies nuclear transfer: implications for embryonic stem cell biology. Cell Stem Cell 2007;1:502-12.

13. Rossant J. Stem cells and lineage development in the mammalian blastocyst. Reprod Fertil Dev 2007:19:111-18.

14. McLaren A. Free range eggs? Science 2007;316:339

15. Chen $\mathbf{Y}, \mathrm{He} Z \mathbf{Z}$, Liu A, et al. Embryonic stem cells generated by nuclear transfer of human somatic nuclei into rabbit oocytes. Cell Res 2003;13:251-63.

16. Illmensee K, Levanduski M, Zavos PM. Evaluation of the embryonic preimplantation potential of human adult somatic cells via an embryo interspecies bioassay using bovine oocytes. Fertil Steril 2006;85:1248-60.

17. Minger S. Interspecies SCNT-derived human embryos - a new way forward for regenerative medicine. Regenerative Med 2007;2:103-6.

18. Byrne JA, Pederson DA, Mitalipov SM, et al. Producing primate embryonic stem cells by somatic cell nuclear transfer. Nature 2007;450:497-502.

19. Human Fertilisation and Embryo Authority. HFEA Statement on licensing of applications to carry out research using human-animal cytoplasmic hybrid embryos. 17 January 2008. http://www.hfea.gov.uk/en/1640.html (accessed 24 Sep 2008).

20. Human Fertilisation and Embryo Authority. HFEA license Committee for Lyle Armstrong's group. 28 November 2007 http://www.hfea.gov.uk/docs/ HFEA Licence Committee minutes for R0179

Newcastle - November 2007 and January 2008.pdf (accessed 24 Sep 2008)

21. Human Fertilisation and Embryo Authority. HFEA license Committee for Stephen Minger's group. 28 November 2007. http://www.hfea.gov.uk/docs/

HFEA_Licence_Committee_minutes_for_R0180_Kings_-

_November_2007_and_January_2008.pōpdf (accēessed 24 Sep 2008).
22. Hall VJ, Compton D, Stoijkovic $P$, et al. Developmental competence of human in vitro aged oocytes as host cells for nuclear transfer. Human Reprod 2007;22:52-62.

23. Lavoir MC, Weier J, Conaghan J, et al. Poor development of human nuclear transfer embryos using failed fertilized oocytes. Reprod Biomed Online 2005;11:740-4.

24. Egli D, Rosains J, Birkhoff G, et al. Developmental reprogramming after chromosome transfer into mitotic mouse zygotes. Nature 2007;447:679-85.

25. Takahashi K, Yamanaka S. Induction of pluripotent stem cells from mouse embryonic and adult fibroblast cultures by defined factors. Cell 2006;126:663-76.

26. Takahashi $\mathbf{K}$, Tanabe $\mathrm{K}$, Ohnuki $\mathrm{M}$, et al. Induction of pluripotent stem cells from adult human fibroblasts by defined factors. Cell 2007;131:861-72.

27. Yu J, Vodyanik MA, Smuga-Otto K, et al. Induced pluripotent stem cell lines derived from human somatic cells. Science 2007;318:1917-20.

28. Gottweis $\mathbf{H}$, Minger S. iPS cells and the politics of promise. Nat Biotechnol 2008;26:271-2.

29. Camporesi S. The context of embryonic development and its ethical relevance. Biotechn J 2007;2:1147-53.

30. Cervera RP, Stojkovic M. Human embryonic stem cell derivation and nuclear transfer: impact on regenerative therapeutics and drug discovery. Clin Pharmacol Ther 2007:82:310-5.

31. Beyhan Z, lager $A E$, Cibelli JB. Interspecies nuclear transfer: implications for embryonic stem cell biology. Cell Stem Cell 2007;1:502-12.

32. Practice Committee of the American Society for Reproductive Medicine Ovarian hyperstimulation syndrome. Fertil Steril 2006;86(5 Suppl):178-83.

33. The Ethics Committee of the American Society for Reproductive Medicine Financial incentives in recruitment of oocyte donors. Fertil Steril 2000;74:216-20.

34. Magnus D, Cho MK. Issues in oocyte donation for stem cell research. Science 2005;308:1747-8.

35. Nussbaum MC. Hiding from humanity. Disgust, shame, and the law. Princeton: Princeton University Press, 2004.

36. Boniolo G. Methodological hints concerning the ethical and social implications of protocells. In: Bedau MA, Parke E, eds. The social and ethical implications of the creation of living technology. Cambridge (Mass.): MIT Press, 2008. In press.

37. Boniolo G, Valentini S. Vaguennes, Kant, and topology. A study of formal epistemology. J Phil Logic 2008;37:141-68.

38. Bortolotti L, Harris H. Disability, enhancement and the harm-benefit continuum. in Spencer J, Pedain A, eds. Freedom and responsibility in reproductive choice. Oxford and Oregon: Hart Publishing, 2006:31-49.

39. Gould SJ. Non moral nature. Nat Hist 1982;91:19-26.

40. Putnam H. Ethics without ontology. Harvard: Harvard University Press, 2004.

41. Editorial. Defining 'natural'. Visceral reactions to an act should not distract from the real ethical issues. Nature 2008;452:665-6.| doi:10.1038/452665b. 
25. Lendemeijer B. Het gebruik van separatie in de psychiatrie: Motieven en redenen van verpleegkundigen. [Utilization of seclusion. Motives and reasons of nurses] Verpleegkunde 1997;12:217-26. Dutch.

26. Mason T. An ethnomethodological analysis of the use of seclusion. J Adv Nurs 1997;26:780-9.

27. Campbell AV. Dependency: the foundational value in medical ethics. In: Fulford KWM, et al., eds Medicine and moral reasoning. Cambridge: Cambridge UP, 1994:184-92.

28. Soloff PH. Historical notes on seclusion and restraint. In: Tardiff K, ed. The psychiatric uses of seclusion and restraint. Washington, DC: American Psychiatric Press, 1984:1-10.

29. Beauchamp TL, Childress JF. Principles of biomedical ethics. $5^{\text {th }}$ edition. Oxford: Oxford UP, 2001

30. Verkerk MA. The care perspective and autonomy. Med Health Care Philos 2001:4:289-94.

31. Muir-Cochrane EC, Holmes CA. Legal and ethical aspects of seclusion: an Australian perspective. J Psychiatr Ment Health Nurs 2001;8:501-6.

32. American Psychiatric Association, American Psychiatric Nurses Association and the National Association of Psychiatric Health Systems. Learning from each other, success stories and ideas for reducing restraint/seclusion in behavioral health. 2003. Available at: http://www.naphs.org/rscampaign/Learning.pdf (accessed 10 Sep 2008).

33. Council of Europe Convention of Biomedicine. Convention for the protection of human rights and dignity of the human being with regard to the application of biology and medicine: convention on human rights and biomedicine (adopted by the Committee of Ministers on 19 November 1996). Hum Reprod 1997;12:2076-80.
34. Pullman D. Universalism, particularism and the ethics of dignity. Christ Bioeth 2001;7:333-58.

35. Pullman D. Human dignity and the ethics and aesthetics of pain and suffering. Theor Med Bioeth 2002:23:75-94.

36. Nordenfelt L. The varieties of dignity. Health Care Anal 2004;12:69-81; discussion 83-9.

37. Schröder A, Ahlstrom G, Larsson BW. Patients' perceptions of the concept of the quality of care in the psychiatric setting: a phenomenographic study. J Clin Nurs 2006;15:93-102.

38. Hoekstra T, Lendemeijer HH, Jansen MG. Seclusion: the inside story. J Psychiatr Ment Health Nurs 2004:11:276-83.

39. Lendemeijer B. Seclusion in psychiatry - aspects of decision making. Utrecht: Publicard, 2000.

40. Kingdon D, Jones R, Lonnqvist J. Protecting the human rights of people with mental disorder: new recommendations emerging from the Council of Europe. Br J Psychiatry 2004:185:277-9.

41. Meehan T, Bergen H, Fjeldsoe K. Staff and patient perceptions of seclusion: has anything changed? J Adv Nurs 2004;47:33-8.

42. Gutheil TG, Tardiff K. Indications and contraindications for seclusion and restraint. In: Tardiff K, ed. The Psychiatric uses of seclusion and restraint. Washington, DC: American Psychiatric Press, 1984:19-34.

43. Sailas $\mathbf{E}$, Fenton M. Seclusion and restraint for people with serious mental illnesses. Cochrane Database Syst Rev 2000;:CD001163.

44. Citizens Commission on Human Rights. Deadly restraints, psychiatry's "therapeutic"assault. Report and recommendations on violent and dangerous use of restraints in mental health facilities. 2004. Available to purchase online: http://www. cchr.org/index/5276/6683/6694 (accessed 15 Aug 2008).

\section{Correction}

doi: 10.1136/jme.2008.024877corr1

Camporesi S, Boniolo G. Fearing a non-existing minotaur? The ethical challenges of research on cytoplasmic hybrid embryos. $J$ Med Ethics 2008;34:821-5. The last paragraph on page 824 was a post-acceptance addition to the paper by the author and as such should have been headed "Note added in proof". 